\title{
IMPLEMENTASI HUTAN TANAMAN RAKYAT DI KABUPATEN PESISIR BARAT-LAMPUNG DAN KABUPATEN TEBO-JAMBI (Implementation of Community Timber Plantation in Pesisir Barat District-Lampung and Tebo District-Jambi)
}

\author{
Sanudin $^{1 *}$, San Afri Awang ${ }^{2}$, Ronggo Sadono ${ }^{2}$ dan Ris Hadi Purwanto ${ }^{2}$ \\ ${ }^{1}$ Program Doktor Ilmu Kehutanan, Fakultas Kehutanan, Universitas Gadjah Mada, \\ Jl. Agro No.1 Bulaksumur, Yogyakarta 55281. \\ 2 Fakultas Kehutanan, Universitas Gadjah Mada, Jl. Agro No.1 Bulaksumur, Yogyakarta 55281. \\ *Penulis korespondensi. Tel: 0265-771352. Email: sanevafa2014@gmail.com.
}

Diterima: 17 April 2015

Disetujui: 20 Mei 2015

\begin{abstract}
Abstrak
Pembangunan Hutan Tanaman Rakyat (HTR) merupakan upaya pemerintah dalam rangka meningkatkan partisipasi dan tanggung jawab masyarakat sekitar hutan dalam pengelolaan hutan dengan didasari oleh prinsip-prinsip pengelolaan hutan produksi. Penelitian ini bertujuan untuk mengetahui implementasi HTR pada koperasi yang mendapatkan Pinjaman Dana Bergulir (PDB) dari Pusat Pembiyaan Pembangunan Hutan (PPPH). Penelitian dilakukan pada bulan Oktober 2014 - Januari 2015 di KLL, Kabupaten Pesisir Barat, Provinsi Lampung dan KMB, Kabupaten Tebo, Provinsi Jambi. Data primer seperti pengelolaan HTR, kinerja PDB, dan permasalahan yang dihadapi dikumpulkan melalui wawancara dengan pengelola koperasi, pejabat di Balai Pemantauan Pemanfaatan Hutan Produksi (BP2HP), Dinas Kehutanan Kabupaten/Provinsi, petani dan melalui pengamatan lapangan. Data yang terkumpul kemudian dianalisis secara deskriptif. Hasil penelitian menunjukkan bahwa tingkat penerimaan masyarakat terhadap program HTR masih rendah akibat kurang maksimalnya kegiatan sosialisasi. Hal ini menyebabkan konflik dalam implementasi HTR. Berdasarkan kondisi lapangan dan tantangan yang dihadapi, tingkat keberhasilan implementasi HTR di KLL sangat tergantung kepada kesungguhan pihak koperasi dalam melakukan teknik silvikultur dalam pengelolaan hutan berbasis masyarakat, sementara implementasi HTR di KMB dari sisi silvikultur sudah cukup baik namun perlu pendekatan persuasif dalam penanganan masalah sosial. Sifat dari PDB adalah untuk memperkuat modal, oleh karena itu koperasi HTR harus mencari sumber permodalan lainnya baik lembaga keuangan maupun pihak swasta lainnya.
\end{abstract}

Kata kunci: hutan tanaman rakyat, implementasi, pinjaman dana bergulir.

\begin{abstract}
Development of Community Timber Plantation (HTR) is government effort to increase participation and responsibility of community around the forest on forest management based on management production forest. This study aimed is to know HTR implementation of cooperative which get revolving fund scheme (PDB-HTR) from Forest Development Funding Center (PPPH). The study was conducted in October 2014 to January 2015 in KLL, Pesisir Barat District, Lampung and KMB, Tebo District, Jambi. Primary data such as HTR management, PDB-HTR performance, and problems faced were collected through interviews with cooperative management, Agency for Monitoring Production Forest Utilization (BPPHP), Provincial/District Forestry Services, farmers and through field observations. Data was analyzed using descriptive. The results showed that farmer acceptance on HTR program is low level because of lack of socialization. It causes conflict on HTR implementation. Based on field conditions and challenges faced, success rate of HTR implementation in KLL is dependent upon seriousness of cooperative on applied silviculture technique, while KMB has been applied a good silviculture technique but it needs a persuasive approach to handled social problems. PDB-HTR has characteristic to sthrengthening capital, therefore HTR Cooperative needs to find the other source of capital (financial institution or private).
\end{abstract}

Keywords: implementation, community timber plantation, revolving fund scheme.

\section{PENDAHULUAN}

Pembangunan Hutan Tanaman Rakyat (HTR) merupakan upaya pemerintah dalam rangka meningkatkan partisipasi dan tanggung jawab masyarakat sekitar hutan dalam pengelolaan hutan dengan didasari oleh prinsip-prinsip pengelolaan hutan produksi (Hakim, 2009; Noordwijk dkk.,
2007). Kebijakan pembangunan HTR pada intinya memberikan peluang kepada masyarakat dalam kegiatan pembangunan hutan tanaman atas akses legal melalui pemberian izin pengelolaan (Rumboko dkk., 2013), akses kelembagaan keuangan yang diwujudkan dalam bentuk pemberian pinjaman dana bergulir, dan akses ke 
pasar untuk mendapatkan harga kayu yang paling menguntungkan (Subarudi, 2014).

Obidzinski dan Dermawan (2010) menyebutkan bahwa kebijakan HTR mempunyai banyak keunggulan di antaranya adalah areal yang dicadangkan oleh pemerintah cukup luas, tersedia fasilitas pinjaman permodalan dari pemerintah, terdapat pilihan pola pengembangan (mandiri, kemitraan, dan developer), dan terdapat jaminan dari pemerintah terkait pasar kayu. Menurut Rumboko dkk. (2013), masalah dalam implementasi kebijakan pengelolaan hutan berbasis masyarakat berkaitan dengan ketimpangan distribusi dan alokasi manfaat sosial ekonomi dan pengembangan kelembagaan khususnya pada tingkat lokal.

Beberapa permasalahan yang dihadapi dalam implementasi HTR diantaranya adalah proses perizinan yang panjang sampai 3 tahun seperti dikemukakan oleh Iskandar dkk. (2013) untuk kasus di Kalimantan Timur dan Suhirman dkk. (2012) untuk kasus di Sulawesi Tenggara dan belum ada kejelasan mekanisme penyaluran kredit HTR (Herawati dkk., 2010). Pemerintah Kabupaten untuk kasus di Sulawesi Selatan menurut Mas'ud dan Malamassam (2011) belum memberikan perhatian terhadap porsi anggaran pembangunan HTR. Schneck (2009) mengidentifikasi bahwa salah satu tantangan dalam mengimplementasikan kebijakan HTR adalah kemampuan masyarakat yang masih rendah dan dukungan pemerintah yang belum maksimal.

Proses pembiayaan melalui pihak bank cukup rumit sementara posisi tawar sektor kehutanan juga lemah sehingga usaha hutan tanaman terkesan tidak menguntungkan dan penuh resiko, kondisi tersebut menyebabkan dunia usaha kehutanan kurang tertarik untuk berhubungan dengan bank (Hakim, 2009; Nugroho, 2011). Herawati (2011) dan Irawanti dkk. (2008) menyatakan bahwa permasalahan permodalan HTR dapat diatasi salah satunya dengan menggunakan pinjaman dana bergulir (PDB) dari Badan Layanan Umum (BLU) Pusat Pembiyaan Pembangunan Hutan (PPPH). BLU PPPH menyediakan pinjaman dengan suku bunga rendah dibandingkan dengan suku bunga komersial (Obidzinski dan Dermawan, 2010).

Peraturan Menteri Kehutanan (Permenhut) No P.23/Menhut-II/2014 tentang Perubahan Atas Permenhut No P.36/Menhut-II/2012 tentang Tata Cara Penyaluran dan Pengembalian Dana Bergulir untuk Kegiatan Rehabilitasi Hutan dan Lahan mengatur pemberian fasilitas PDB untuk semua pembangunan dan pemeliharaan hutan baik HTR, Hutan Kemasyarakatan (HKm), Hutan Desa (HD), maupun Hutan Rakyat (HR). Untuk HTR sendiri, skema PDB HTR sudah diatur sejak 2008 dengan adanya Keputusan Kepala Pusat P2H No. 01/Pusat P2H-1/2008. Penelitian ini bertujuan untuk mengetahui implementasi HTR pada koperasi HTR yang mendapatkan PDB dari BLU PPPH.

\section{METODE PENELITIAN}

\section{Waktu dan Lokasi}

Penelitian dilakukan pada bulan Oktober 2014 - Januari 2015 di KLL, Kabupaten Pesisir Barat, Provinsi Lampung dan KMB, Kabupaten Tebo, Provinsi Jambi. Kedua koperasi tersebut dipilih dengan pertimbangan karena sudah mendapatkan fasilitas PDB dari BLU PPPH dalam pengelolaan HTR-nya.

\section{Pengumpulan dan Analisis Data}

Data yang dikumpulkan terdiri dari data primer dan data sekunder. Data primer seperti pengelolaan HTR, kinerja penggunaan PDB, dan permasalahan yang dihadapi dikumpulkan melalui wawancara dengan pengurus koperasi HTR, pejabat Balai Pemantauan Pemanfaatan Hutan Produksi (BP2HP) Wilayah VI Lampung dan Wilayah IV Jambi, pejabat di Dinas Kehutanan Kabupaten/provinsi, petani penggarap dan melalui pengamatan lapangan.

Data sekunder seperti Rencana Karya Tahunan (RKT) dan Rencana Karya Usaha (RKU) Izin Usaha Pemanfaatan Hasil Hutan Kayu (IUPHHK) HTR dikumpulkan dari koperasi HTR dan BP2HP. Data yang terkumpul kemudian dianalisis secara deskriptif.

\section{HASIL DAN PEMBAHASAN}

Implementasi HTR di KLL, Kabupaten Pesisir Barat, Provinsi Lampung dan KMB, Kabupaten Tebo, Provinsi Jambi yang dibahas dalam tulisan ini terdiri dari kondisi HTR, kinerja PDB HTR, dan permasalahan yang dihadapi serta alternatif pemecahan masalah.

\section{KLL, Kabupaten Pesisir Barat, Lampung}

\section{Kondisi HTR}

Herawati (2013) telah menganalisis kelayakan finansial HTR di Provinsi Lampung dengan menggunakan dua jenis pohon cepat tumbuh yakni sengon dan jabon yang mempunyai daur tebang 6-8 tahun. Hasil analisisnya menunjukkan bahwa usaha HTR di Provinsi Lampung layak dengan nilai NPV sebesar Rp 9.911.550, BCR sebesar 2,13 dan IRR sebesar $19 \%$.

Areal Izin Usaha Pemanfaatan Hasil Hutan Kayu pada HTR (IUPHHK-HTR) KLL di Kabupaten Pesisir Barat merupakan Hutan Produksi 
Tebatas (HPT) yang berbatasan dengan Taman Nasional Bukit Barisan Selatan, Areal Penggunaan Lain (APL) serta Hutan Lindung. Areal ini termasuk ke dalam DAS Way Mahnaibalak, Way Mahnaitengah, Way Mahnailunik dengan jenis tanah terdiri dari dystropepts, tropodults, humitropepts, dan eutropepts (Anonim, 2013).

Hasil pengamatan lapangan diketahui bahwa kondisi penutupan lahan areal koperasi tersebut terdiri dari hutan primer, hutan sekunder, semak belukar, dan hutan yang ditumbuhi jenis damar (Shorea spp) yang getahnya dimanfaatkan oleh masyarakat. Rotan (Calamus sp.) masih banyak ditemukan di areal IUPHHK HTR namun jarang dimanfaatkan karena tidak ada pasar. Ada sebagian masyarakat yang membuka kawasan hutan dan menanam jenis coklat maupun karet.

KLL yang berdiri dengan akta pendirian perusahaan dengan No 133/BH/X.4/II.06/XI/2010 tanggal 10 November 2010 memegang IUPHHKHTR dengan areal seluas \pm 675 ha berdasarkan SK Bupati Kabupaten Lampung Barat No B/121/KPTS/II.14/2012 tanggal 7 Maret 2012. Menurut Herawati (2013), berdasarkan kondisi perkembangannya, pengelolaan kegiatan HTR LL termasuk dalam kategori stagnan, yakni koperasi yang belum memulai aktivitasnya setelah izin diperoleh.

\section{Kinerja PDB}

Menurut Permenhut No P.36/Menhut-II/2012, jaminan atau agunan bagi pelaku usaha HTR skema PDB adalah tegakan hasil pembangunan tanaman (Pasal 15 ayat 1 (e)) dengan besarnya pinjaman maksimal adalah 300 ha dikalikan biaya kegiatan per ha (Pasal 29 (3)) dengan jangka waktu maksimum adalah 8 tahun. Komponen dan standar biaya kegiatan pembangunan HTR disajikan pada Tabel 1.

Sesuai dengan Surat Keterangan Notaris dan PPAT No 50/KET/PPAT-MD/II/2014 tanggal 6 Februari 2014, KLL memperoleh PDB untuk pembiyaan pembangunan HTR dengan nilai komitmen Rp 2.559.570 yang disalurkan secara bertahap. Penyaluran tahap I sudah dicairkan pada Bulan Maret 2014 sebesar Rp 237.235.000 dengan rincian sebagai berikut: Rp 101.910.000 untuk membiayai pengadaan bibit sebanyak 20.000 batang dan Rp 135.325.000 untuk persiapan lahan seluas 50 ha (Anonim, 2014 ).

Sampai September 2014, kinerja pengelolaan HTR oleh KLL berupa pembuatan persemaian dengan jumlah bibit sebanyak \pm 17.000 batang dengan tinggi rata-rata $25-40 \mathrm{~cm}$, luas persemaian 2,08 ha, dan kegiatan persiapan lahan (pembersihan lahan) terdiri dari Blok 1 (54 jalur, luas 5,4 ha, belum dibuat lubang tanam), Blok 2 (69 jalur, luas
Tabel 1. Komponen dan standar biaya kegiatan pembangunan HTR.

\begin{tabular}{llr}
\hline No. & \multicolumn{1}{c}{ Komponen biaya } & \multicolumn{1}{c}{$\begin{array}{c}\text { Biaya } \\
\text { satuan } \\
\text { HTR (Rp) }\end{array}$} \\
\hline A. $\quad$ Penanaman & 2.038 .200 \\
& 1. Persemaian dan pembibitan & 2.706 .500 \\
& 2. Persiapan lahan & 575.700 \\
3. Penanaman & \\
B. Pemeliharaan & 911.200 \\
1. Pemeliharaan tahun I & 717.700 \\
2. Pemeliharaan tahun II & 630.000 \\
3. Pemeliharaan tahun III & 358.300 \\
4. Pemeliharaan lanjutan I & 179.100 \\
5. Pemeliharaan lanjutan II & \\
Perlindungan dan pengamanan hutan & 219.200 \\
1. Pengendalian hama dan penyakit & 93.000 \\
2. Pengendalian kebakaran & 103.000 \\
\hline 3. Pengamanan hutan & 8.531 .900 \\
\hline Total (A + B + C) &
\end{tabular}

Sumber: Peraturan Kepala PPPH No P.01/P2H-1/2010.

6,4 ha), Blok 3 (1 jalur, luas 2,08 ha, land clearing), dan Blok 4 (1 jalur, luas 0,95 ha, land clearing).

Hasil evaluasi yang dilakukan oleh Anonim (2014 ) terhadap pengelolaan HTR diatas diketahui bahwa terdapat kekurangan pengadaan bibit sebanyak 3.000 batang dan terdapat kekurangan persiapan lahan seluas 34,75 ha, pada semua jalur harus dibuat lubang tanam dengan ukuran $30 \mathrm{~cm} \mathrm{x}$ $30 \mathrm{~cm}$ x $30 \mathrm{~cm}$ sebanyak 20.000 lubang. Berdasarkan evaluasi kinerja tersebut, BLU PPPH belum dapat merealisasikan pencairan pinjaman tahap 2. Hasil pengecekan lapangan dibandingkan dengan RKT terdapat ketidaksesuaian antara persemaian yang sudah dibuat (di blok 2) yang seharusnya di blok 1 sesuai dengan RKT dan kegiatan persiapan lahan (pembuatan jalur tanam) yang seharusnya di blok 1 . Hal ini diduga karena pengurus koperasi belum mengetahui kondisi lapangan sebelum menyusun RKT.

Jenis tanaman di persemaian adalah afrika (Maesopsis eminii), sengon (Paraserianthes falcataria), dan damar (Shorea spp). Jenis afrika dan sengon dipilih karena merupakan jenis tanaman cepat tumbuh, sedangkan damar merupakan jenis yang disukai masyarakat Kabupaten Pesisir Barat yang tumbuh baik di kawasan hutan. Hasil wawancara dengan Ash Siddik Maulana (Sekretaris KLL) pada tanggal 27 Januari 2015 diketahui bahwa kegiatan persiapan lahan seperti penebasan dan pembuatan lubang tanam dilakukan dengan sistem borongan dengan upah Rp 2.000.000/ha dan tenaga kerja yang digunakan didatangkan dari daerah lain (di luar kabupaten) karena pengurus koperasi kesulitan mendapatkan tenaga kerja, sementara kegiatan penanaman menggunakan 
tenaga kerja dari masyarakat penggarap lahan areal HTR dengan sistem upah Rp 500/batang.

Blok penanaman dibuat dengan sistem jalur dengan lebar \pm 3 dan tanaman ditanam di sisi jalur dengan jarak tanam $3 \times 3 \mathrm{~m}$. Lubang tanam yang dibuat belum sesuai dengan standar dan jenis yang ditanam harus bersaing dengan rumput dan gulma lainnya untuk mendapatkan sinar matahari dan unsur hara. Kondisi ini menyebabkan persentase tumbuh bibit yang ditanam menjadi rendah.

\section{Permasalahan yang Dihadapi dan Alternatif Pemecahannya}

Beberapa permasalahan yang dihadapi dalam pengelolaan IUPHHK-HTR KLL di antaranya adalah konflik antara KLL dan petani penggarap, pemahaman dan pelibatan petani penggarap yang masih kurang, dan pengelolaan aspek silvikultur. Ketika KLL mendapat IUPHHK-HTR dari Bupati Pesisir Barat pada tahun 2012, sebagian besar petani penggarap (68\%) yang sebelumnya sudah melakukan penggarapan lahan di areal IUPHHKHTR KLL pada tahun 2013 mengajukan usulan kepada Bupati Pesisir Barat untuk membatalkan IUPHHK-HTR KLL karena menganggap KLL akan mengambil lahan yang sudah lama mereka garap, namun usulan tersebut ditolak oleh Bupati Pesisir Barat.

Ketika dilakukan pembukaan lahan untuk lahan persemaian KLL kurang lebih seluas 2 ha pada Bulan April 2015, petani penggarap menduga KLL sudah menebang 5 anakan pohon damar (Shorea spp), namun menurut pengakuan KLL anakan pohon damar tersebut sudah dipindahkan dan ditanam ke tempat lain. Konflik lainnya adalah pelaporan KKL kepada pihak yang berwajib oleh petani penggarap karena KLL diduga telah menebang satu batang pohon damar yang sudah menghasikan getah. Penebangan tersebut dilakukan pada saat pembukaan lahan sebelum melakukan penananaman. Pohon damar yang dapat dimanfaatkan getahnya bagi masyarakat Pesisir Barat merupakan sumber mata pencaharian utama.

Pemahaman petani penggarap yang sudah lebih dahulu membuka kawasan hutan terhadap konsep HTR masih rendah sehingga tingkat penerimaan petani penggarap terhadap HTR sebagian besar negatif. Petani penggarap tersebut berasal dari dari 4 kecamatan yakni Kecamatan Pesisir Tengah, Pesisir Selatan, Ngambur, dan Kecamatan Karya Penggawa. Hal ini menunjukkan bahwa kegiatan sosialisasi yang dilakukan baik oleh pengurus KLL maupun instansi terkait lainnya terhadap petani penggarap belum efektif.

Konflik tersebut bermula pada saat proses pengusulan lokasi penunjukkan HTR oleh KLL tanpa melibatkan petani penggarap, sehingga petani penggarap mengalami ketakutan lahan garapannya akan diambil alih oleh KLL. Kegiatan sosialisasi tentang konsep HTR terhadap petani penggarap baru dilakukan setelah KLL mendapatkan Penetapan Areal Kerja (PAK) dari Menteri Kehutanan dan IUPHHK-HTR dari Bupati Pesisir Barat. Dalam proses implementasi HTR selanjutnya, penentuan jenis pohon yang diusahakan oleh KLL yakni afrika (Maesopsis eminii), sengon (Paraserianthes falcataria), dan damar (Shorea spp) hanya ditentukan oleh pihak KLL sendiri tanpa melibatkan petani penggarap. Petani penggarap tidak menyetujui sepenuhnya pemilihan jenis tersebut, mereka menganggap bahwa jenis afrika tidak cocok dengan kondisi biofisik IUPHHK-HTR KLL.

Penutupan lahan IUPHHK-HTR KLL terdiri dari hutan primer, hutan sekunder, hutan yang ditanami damar, dan semak belukar. Kondisi tersebut memberikan tantangan tersendiri bagi KLL untuk memastikan jenis pohon yang ditanam dapat tumbuh dengan baik. Berdasarkan pengamatan lapangan, jenis pohon yang ditanam (afrika, damar, dan sengon) mempunyai persentase tumbuh yang rendah akibat kondisi fisik di lapangan dimana persaingan antara jenis yang ditanam dengan gulma dan tanaman lainnya untuk mendapatkan sinar matahari dan unsur hara tanah sangat tinggi.

Beberapa alternatif pemecahan masalah tersebut di antaranya melalui kegiatan sosialisasi, pelibatan petani penggarap secara aktif dalam setiap tahapan pengelolaan HTR, pemahaman terhadap jenis lokal yang disukai masyarakat seperti durian (Durio zibethinus), petai (Parkia speciosa), dan damar (Shorea spp), dan pengelolaan terhadap aspek silvikultur. Sosialisasi yang dilakukan oleh koperasi HTR, Dinas Kehutanan Kabupaten, BP2HP dan Balai Pemantapan Kawasan Hutan (BPKH) terkait konsep HTR dan batas kawasan harus dilakukan lebih sering agar petani penggarap mempunyai pemahaman yang sama. Pelibatan petani penggarap secara lebih aktif dalam tiap tahapan pengelolaan HTR menjadi sangat penting karena pengurus KLL merupakan orang luar yang justru tidak mempunyai lahan garapan di areal IUPHHK-HTR sekaligus untuk mengakomodasi hak-hak petani penggarap dalam rangka mengurangi konflik yang ada.

Dalam kegiatan persiapan lahan, tenaga upahan (dari luar kabupaten) diharapkan dapat menghindari penebangan terhadap jenis petai, durian dan damar yang sudah tumbuh sebelumnya untuk menghindari konflik dengan petani penggarap karena ketiga jenis tersebut merupakan jenis yang disukai petani penggarap. Demikian halnya dengan kesungguhan pihak KLL dalam menangani aspek silvikultur pengelolaan hutan 
dengan tantangan biofisik lapangan yang ada menjadi sangat penting. Kesungguhan tersebut dapat diwujudkan melalui kegiatan persiapan lahan (pembersihan), pembuatan lubang tanam sesuai standar yang sudah ditentukan, penggunaan bibit yang berkualitas, dan kegiatan pemeliharaan seperti pemupukan, penyiangan (pembersihan lahan), penyulaman untuk bibit yang mati, dan pengendalian hama dan penyakit.

\section{KMB, Kabupaten Tebo Ulu, Jambi Kondisi HTR}

KMB berdiri pada tahun 2009 dengan nota pendirian sesuai SK No 32/BH/Kop-UKM/IV/2009 tanggal 14 April 2009. Koperasi ini mendapat SK IUPHHK-HTR 05/Dinhut/2010 tanggal 22 Januari 2010 dengan luas areal 2.263,74 ha. Areal IUPHHK KMB termasuk dalam kelompok hutan pasir mayang danau bangko dengan keadaan lahan berupa lahan kering (mineral) dan penutupan lahan berupa semak belukar (Anonim, 2012).

Beberapa kegiatan yang sudah dilakukan oleh koperasi dalam pengelolaan HTR diantaranya adalah areal IUPHHK-HTR dengan topografi datar sampai berbukit sebagian besar sudah dibuka dengan cara land clearing, pembuatan jalan yang berfungsi sebagai sarana transportasi dan batas blok dengan lebar \pm 6-8 $\mathrm{m}$ menggunakan alat berat seperti eksavator, dan kegiatan penanaman karet (Hevea braziliensis) dan jabon putih (Anthocephalus cadamba) untuk 4 RKT masingmasing seluas 50 ha/tahun.

Berdasarkan hasil wawancara dengan M. Azri (Ketua KMB) pada tanggal 24 November 2012, jabon dipilih dengan beberapa pertimbangan diantaranya mempunyai pertumbuhan batang lebih cepat, dapat dipanen pada umur 5-6 tahun, permintaan pasar sangat tinggi, dan tahan terhadap serangan hama dan penyakit. Sementara karet dipilih dengan pertimbangan mempunyai prospek yang menguntungkan dan jenis ini sangat disukai oleh masyarakat Jambi. Kegiatan penanaman menggunakan tenaga kontrak/upahan, bibit jabon dan karet diperoleh dengan cara membeli dan tidak melakukan pembibitan sendiri karena keterbatasan sumberdaya manusia.

KMB menerapkan dua skema dalam pengelolaan IUPHHK HTR-nya yakni mengajak petani penggarap yang sudah ada untuk terlibat dan masuk dalam keanggotaan koperasi dengan skema bagi hasil 30\% (koperasi) : 70\% (petani penggarap), jika petani penggarap tidak mengikuti skema tersebut, maka lahan yang sudah digarap petani akan dilakukan ganti rugi oleh koperasi dan selanjutnya tanaman yang ada menjadi milik koperasi. Kondisi ini sempat menimbulkan konflik antara koperasi dan petani penggarap karena komunikasi, koordinasi, dan transparansi yang masih lemah.

\section{Kinerja PDB}

Luas areal yang disetujui BLU PPPH terhadap KMB untuk mendapatkan fasilitas pinjaman dana bergulir adalah 300 ha yang terdiri dari 6 petak dimana masing-masing petak seluas 50 ha yang akan disalurkan dalam 11 tahap. Jenis yang ditanam adalah karet dengan jumlah tanaman sejumlah 25.000 batang per petak atau 150.000 batang untuk 6 petak. Data sampai Bulan Desember 2014, PDB yang sudah disalurkan ke KMB sudah 4 tahap seperti disajikan pada Tabel 2.

Jumlah PDB dan bunga yang digulirkan ke KMB dengan jangka waktu pinjaman selama 12 tahun dan suku bunga sebesar $7 \%$ per tahun (Anonim, 2012) disajikan pada Tabel 3.

Tabel 2. Penyaluran PDB ke KMB.

\begin{tabular}{llcccc}
\hline Komponen biaya & Petak & $\begin{array}{c}\text { Biaya satuan } \\
\text { HTR (Rp) }\end{array}$ & $\begin{array}{c}\text { Luas } \\
\text { (ha) }\end{array}$ & $\begin{array}{c}\text { Pinjaman } \\
\text { disalurkan (Rp) }\end{array}$ & yang \\
\hline Tahap 1 (2010-2011) & I & 6.300 .800 & 50 & 315.040 .000 \\
Tahap II (2011-2012) & I,II & 7.087 .700 & 50 & 354.385 .000 \\
Tahap III (2012-2013) & I, II, III & 7.786 .900 & 50 & 389.345 .000 \\
Tahap IV (2013-2014) & I, II, III, IV & 8.214 .400 & 50 & 410.720 .000 \\
\hline
\end{tabular}

Sumber: Anonim, 2010.

Tabel 3. Jumlah PDB dan bunga yang digulirkan ke KMB.

\begin{tabular}{lllll}
\hline $\begin{array}{l}\text { Jangka } \\
\text { pengembalian }\end{array}$ & $\begin{array}{l}\text { Pokok } \\
\text { (Rp) }\end{array}$ & $\begin{array}{l}\text { Bunga } \\
\text { (Rp) }\end{array}$ & $\begin{array}{l}\text { Total } \\
\text { (Rp) }\end{array}$ & Keterangan \\
\hline Tahun ke-7 (2016) & 426.595 .000 & 162.345 .400 & 588.940 .000 & Petak 1 seluas 50 ha \\
Tahun ke-8 (2017) & 426.595 .000 & 162.345 .400 & 588.940 .000 & Petak 2 seluas 50 ha \\
Tahun ke-9 (2018) & 426.595 .000 & 162.345 .400 & 588.940 .000 & Petak 3 seluas 50 ha \\
Tahun ke-10 (2019) & 426.595 .000 & 162.345 .400 & 588.940 .000 & Petak 4 seluas 50 ha \\
Tahun ke-11 (2020) & 426.595 .000 & 162.345 .400 & 588.940 .000 & Petak 5 seluas 50 ha \\
Tahun ke-12 (2021) & 426.595 .000 & 162.345 .400 & 588.940 .000 & Petak 6 seluas 50 ha \\
\hline \multicolumn{7}{l}{ Total } & 2.559.570.000 & 974.072 .400 & & \\
\hline Sumber: Anonim, 2010, data sampai bulan
\end{tabular}

Sumber: Anonim, 2010, data sampai bulan Desember 2014. 
Berdasarkan pengamatan lapangan, RKT tahun 2010 yang ditanami karet dan jabon dalam waktu sekitar 2 tahun lagi (2016) sudah bisa dipanen. Jika pada tahun 2016 harus mengembalikan pinjaman dan bunganya, perkiraan pendapatan yang diperoleh KMB sebagai berikut:

a. Karet

Dengan jarak tanam 3 x 5 m, maka dalam 1 ha terdapat \pm 667 batang karet, produktivitas karet hanya $60 \%$ dari yang seharusnya yakni 1.600 $\mathrm{kg} / \mathrm{ha} / \mathrm{tahun}$ karena adanya permasalahan kualitas bibit karet, pengelolaan yang kurang maksimal dan penyerapan teknologi yang masih kurang (Riadi dkk., 2011). Dengan harga getah karet saat ini \pm Rp 7.000 - Rp 8.000/kg, luas areal 40 ha, perkiraan pendapatan yang bisa dihasilkan dari getah karet sebagai berikut:

Pendapatan = produktivitas $\mathrm{x}$ luas areal $\mathrm{x}$ harga

$=(960 \mathrm{~kg} / \mathrm{ha}) \times 40$ ha $\times \mathrm{Rp} 7.500 / \mathrm{kg}$

$=\mathrm{Rp}$ 288.000.000.

b. Jabon

Dalam 1 ha lahan, dapat ditanam sebanyak \pm 1.111 batang jabon dengan jarak 3 x $3 \mathrm{~m}$. Menurut Mulyana dkk. (2010), pendapatan per ha yang bisa diperoleh dari pengusahaan jabon putih bisa diperoleh dari hasil penjarangan 1 pada tahun ke-3 dengan volume $30 \mathrm{~m}^{3}$ dan panen akhir pada tahun ke-6 dengan volume $350 \mathrm{~m}^{3}$. Dengan harga jabon saat ini di Provinsi Jambi \pm Rp 600.000/m ${ }^{3}$ (harga tegakan di lokasi) dan luas tanam 10 ha, maka perkiraan pendapatan yang bisa dihasilkan dari pengusahaan jabon sebagai berikut:

Pendapatan $=\{$ (hasil penjarangan + hasil panen akhir) $\} \mathrm{x}$ luas areal

$=\left(30 \mathrm{~m}^{3} \times \mathrm{Rp} 50.000\right)+\left(350 \mathrm{~m}^{3} \mathrm{x}\right.$ Rp 600.000)\} x 10 ha

$=$ Rp 2.115.000.000,-.

Sementara menurut pengalaman PT ASA Forestry di Tasikmalaya (Hani dan Sidiq, 2014), perkiraan pendapatan yang bisa dihasilkan dari pengusahaan jabon sebagai berikut:

Pendapatan $=\{$ (hasil penjarangan + hasil panen akhir) $\}$ x luas areal

$=\left\{\left(80 \mathrm{~m}^{3} \mathrm{x} \mathrm{Rp} 400.000\right)+\left(240 \mathrm{~m}^{3} \mathrm{x}\right.\right.$ Rp 900.000) $\} \times 10$ ha

$=$ Rp 2.480.000.000,-.

Perkiraan penerimaan tersebut sangat tergantung kepada penerapan teknik silvikultur mulai dari pemilihan bibit, pengolahan tanah, pemupukan (sebelum dan sesudah tanam), penyiangan, dan pengendalian hama penyakit.

\section{Permasalahan yang Dihadapi dan Alternatif Pemecahannya}

Beberapa permasalahan yang dihadapi dalam pengelolaan IUPHHK-HTR KMB di antaranya adalah skema bagi hasil 30\% (koperasi) : 70\% (petani penggarap) ditentukan secara sepihak oleh pihak koperasi dan tidak mempunyai dasar dalam penentuannya. Hal ini telah memunculkan konflik antara koperasi dengan petani penggarap. Hubungan antara koperasi dengan Dinas Kehutanan Kabupaten Tebo dengan pihak KMB kurang harmonis akibat kurangnya komunikasi dan koordinasi. Dinas Kehutanan Kabupaten Tebo beranggapan bahwa selama ini pihak koperasi jarang berkoordinasi dalam setiap tahapan pengelolaan HTR.

Untuk mengatasi permasalahan tersebut, penentuan skema bagi hasil antara koperasi dan petani penggarap harus dilakukan secara transparan, mempunyai dasar yang jelas, dan melibatkan Dinas Kehutanan Kabupaten Tebo sebagai pendamping HTR dalam penentuannya. Komunikasi dan koordinasi antara KMB dengan Dinas Kehutanan Kabupaten maupun stakeholder terkait lainnya seperti BP2HP harus dibangun dengan dasar saling percaya dan terbuka.

\section{Perbandingan Implementasi HTR antara KLL dan KMB}

Berdasarkan hasil pengamatan lapangan dan wawancara dengan instansi terkait disajikan perbandingan implementasi HTR KLL dan KMB pada Tabel 4.

Dalam implementasi HTR terdapat pelibatan penyuluh yang mempunyai peran dalam pendampingan baik administratif, teknis maupun kelembagaan. Berdasarkan hasil wawancara dengan Dinas Kehutanan Kabupaten Tebo dan Pesisir Barat, pengurus KLL dan KMB, BP2HP, dan PPPH diketahui bahwa peran penyuluh belum maksimal karena keterbatasan anggaran dan sarana prasarana. Salah satu tugas BP2HP dalam implementasi HTR adalah memfasilitasi penyusunan RKU/RKT pemegang IUPHHK-HTR, sementara tugas Dinas Kehutanan Kabupaten adalah menyiapkan tenaga fasilitator untuk mendampingi pemegang IUPHHKHTR atas fasilitasi dari BP2HP.

Untuk kasus di KMB, hubugan antara Dinas Kehutanan Tebo dan KMB kurang harmonis akibat kurang koordinasi dan komunikasi. Hal ini menyebabkan proses pendampingan tidak berjalan, ada beberapa kegiatan KMB dalam implementasi HTR dilakukan tanpa melibatkan BP2HP Wilayah IV Jambi dan Dinas Kehutanan Kabupaten Tebo, seperti persiapan lahan menggunakan metode land clearing dan penggunaan alat berat yang sebenarnya dalam peraturan implementasi HTR tidak diperkenankan.

Di sisi lain, keterbatasan anggaran yang dimiliki oleh BP2HP Wilayah VI Lampung dan Dinas Kehutanan Kabupaten Pesisir Barat dan lokasi HTR yang cukup jauh (7 jam dari ibukota 
Tabel 4. Perbandingan implementasi antara HTR KLL dan KMB.

\begin{tabular}{|c|c|c|c|c|c|c|}
\hline No & Uraian & & KLL & & KMB & Keterangan \\
\hline 1. & $\begin{array}{r}\text { Aksesibilitas } \\
\text { menuju lokasi }\end{array}$ & $\begin{array}{l}\text { Akses } \\
\text { topografi } \\
\text { curam }\end{array}$ & $\begin{array}{l}\text { sulit } \\
\text { landai }\end{array}$ & $\begin{array}{l}\text { dengan } \\
\text { sampai }\end{array}$ & $\begin{array}{l}\text { Akses mudah, topografi } \\
\text { datar sampai landai }\end{array}$ & $\begin{array}{l}\text { KLL jauh dari } \\
\text { perkampungan, KMB } \\
\text { dekat dan berbatasan } \\
\text { dengan perkampungan }\end{array}$ \\
\hline
\end{tabular}

2. Kondisi areal Hutan primer, hutan Lahan kering (mineral), kelola sekunder, semak belukar semak belukar

3. Kondisi perkembangan

Baru berjalan dengan adanya persemaian, persiapan lahan dan penanaman

Sudah berjalan sejak tahun 2010, tahun 2016 kayu jabon dan getah karet sudah bisa panen

4. Pendampingan

Dinas Kehutanan Kabupaten, BP2HP, dan tenaga lapangan dari BLU $\mathrm{PPPH}$

5. Tingkat
penerimaan petani
penggarap

Sebagian besar petani penggarap tidak setuju dan menolak HTR

6. Pendekatan
penanganan konflik

Persuasif dengan melibatkan tokoh adat dan tokoh masyarakat, potensi konflik sedang

7. Permodalan

Penyaluran PDB dari BLU PPPH baru tahap 1 , masih mengandalkan PDB dari BLU Pusat P2H

Sumber: Data primer, kondisi sampai bulan Januari 2015

provinsi, dan 3 jam dari ibu kota kabupaten) dengan aksesibilitas yang sulit menyebabkan proses pendampingan di KLL belum maksimal. Ada beberapa kegiatan yang dilakukan oleh KLL tidak sesuai dengan perencanaan yang dibuat, misalnya dalam penentuan lokasi persemaian dan lokasi penanaman sesuai RKT. Sejak tahun 2012 terdapat tenaga pendamping (tenaga lapangan) dari PPPH yang mempunyai tugas hanya untuk melakukan pendampingan teknis terkait penyaluran pinjaman dana bergulir, tidak untuk melakukan pendampingan perencanaan HTR secara keseluruhan. Keterbatasan anggaran di Dinas Kehutanan Kabupaten Pesisir Barat juga menyebabkan RKT IUPHHK HTR KLL tahun 2014 sampai saat ini belum disahkan karena pihak Dinas Kehutanan belum melakukan verifikasi lapangan.

Kondisi diatas sejalan dengan Nugroho dkk. (2013) yang menyatakan bahwa fungsi penyuluh dan fasilitator dalam implementasi HTR selama ini belum maksimal. Masih menurut Nugroho dkk. (2013), kehadiran fasilitator sangat strategis, karena fasilitator tidak hanya memberikan panduan teknis tapi juga administratis juga mendorong petani untuk saling menolong satu sama lain dan membangun kepercayaan diantara mereka. Pasal 70 (3) Peraturan Pemerintah No 6 tahun 2007 menyebutkan bahwa pemegang IUPHHK-HTR berhak mendapat pendampingan dalam rangka penguatan kelembagaan oleh bupati atau pejabat yang ditunjuk.

Herawati (2010) menyatakan bahwa minat masyarakat di Kalimantan Selatan cukup tinggi terhadap HTR karena adanya kebutuhan akan lahan, sementara untuk areal HTR KLL (Lampung) dan areal HTR KMB (Jambi) sebagian besar lahan yang dicadangkan sebagai areal HTR telah dikuasai oleh petani penggarap. Hal ini sama dengan kondisi di Kabupaten Sarolangun Jambi seperti dinyatakan 
oleh Febriani dkk. (2012) dimana keikutsertaan masyarakat dalam HTR tidak dipengaruhi oleh kepemilikan lahan mereka, sebagian besar petani penggarap mempunyai ketakutan bahwa pemerintah akan mengambil lahan yang sudah lama mereka garap.

Dalam upaya meredam potensi konflik yang ada, kedua koperasi menggunakan pendekatan yang berbeda. Pengurus KLL menggunakan pendekatan persuasif dengan melibatkan tokoh adat dan tokoh masyarakat, sementara pengurus KMB menggunakan pendekatan represif bahkan dengan melibatkan pihak militer.

Pemberian akses pinjaman dengan subsidi bunga yang seharusnya ditujukan untuk meningkatkan kesejahteraan masyarakat di dalam dan sekitar hutan, pada akhirnya hanya akan dimanfaatkan oleh badan-badan usaha yang berbadan hukum yang umumnya telah mampu mengakses kredit komersial (Nugroho, 2011). Kondisi tersebut berdasarkan pengamatan lapangan ditemukan pada kedua koperasi tersebut dimana ketua kedua koperasi merupakan pemilik modal besar besar dan atau pengusaha yang mempunyai akses untuk mendapatkan permodalan baik dari bank maupun dari lembaga keuangan lainnya.

\section{KESIMPULAN}

Tingkat penerimaan masyarakat terhadap program HTR di kedua koperasi masih rendah akibat kurang maksimalnya kegiatan sosialisasi sehingga menimbulkan konflik dalam implementasi HTR. Tingkat keberhasilan implementasi HTR di KLL sangat tergantung dari kesungguhan pihak koperasi dalam melakukan teknik silvikultur, sementara di KMB memerlukan pendekatan persuasif dalam penanganan masalah sosial yang terjadi. Sifat pinjaman dana bergulir dari BLU PPPH adalah untuk memperkuat modal, oleh karena itu koperasi HTR harus mencari sumber permodalan lainnya baik lembaga keuangan maupun pihak swasta lainnya.

\section{UCAPAN TERIMAKASIH}

Penulis mengucapkan terima kasih kepada Ir. Agus Isnantio Rahmadi, M.Sc. (Kepala Pusat Pembiyaan Pembangunan Hutan), Ash Siddik Maulana, S.TP (Sekretaris Koperasi Labuwai Lestari/KLL, Pesisir Barat, Lampung), dan M. Azri, SH, MH (Ketua Koperasi Maju Bersama/KMB, Tebo, Jambi) atas data dan informasi serta fasilitasi lapangannya.

\section{DAFTAR PUSTAKA}

Anonim, 2010. Penawaran Ketentuan Pinjaman Dana Bergulir Pembiayaan Pembangunan Hutan Tanaman Rakyat An. Koperasi Maju Bersama. Pusat Pembiayaan Pembangunan Hutan (PPPH), Kementerian Kehutanan. Jakarta.

Anonim, 2012. Rencana Kerja Usaha Pemanfaatan Hasil Hutan Kayu pada IUPHHK-HTR Koperasi Maju Bersama Tahun 2012-2013. Tebo.

Anonim, 2013. Rencana Kerja Usaha Pemanfaatan Hasil Hutan Kayu pada HTR Koperasi Labuwai Lestari Tahun 2013-2018. Krui.

Anonim, 2014. Penawaran Ketentuan Pinjaman Dana Bergulir Pembiayaan Pembangunan Hutan Tanaman Rakyat An. Koperasi Labuwai Lestari. Pusat Pembiayaan Pembangunan Hutan (PPPH). Kementerian Kehutanan, Jakarta.

Anonim, 2014 ${ }^{\mathrm{b}}$ Evaluasi Kinerja Debitur Pembangunan HTR An. Koperasi Labuwai Lestari. Pusat Pembiayaan Pembangunan Hutan (PPPH). Kementerian Kehutanan, Jakarta.

Febriani, D., Darusman, D., Nurrochmat, D.R., dan Wijayanto, N., 2012. Strategi Implementasi Kebijakan Hutan Tanaman Rakyat di Kabupaten Sarolangun Jambi. Jurnal Analisis Kebijakan Kehutanan, 9(2):81-95.

Hakim, I., 2009. Kajian Kelembagaan dan Kebijakan Hutan Tanaman Rakyat: Sebuah Terobosan dalam Menata Kembali Konsep Pengelolaan Hutan Lestari. Jurnal Analisis Kebijakan Kehutanan, 6(1):27-41.

Hani, A., dan Sidiq, R.P., 2014. Bisnis Jabon Tanpa Modal. Padi, Jakarta.

Herawati, T., Widjayanto, N., Saharuddin, dan Eriyatno, 2010. Analisis Respon Pemangku Kepentingan di Daerah terhadap Kebijakan Hutan Tanaman Rakyat. Jurnal Analisis Kebijakan Kehutanan, 7(1):13-25.

Herawati, T., 2013. Techical Report: Economic Study and Standar Price of Community Based Plantation Forest (HTR) Products Case Study in Lampung. ITTO CFM-PD 001/10 REV.2 (F): "Strengthening Capacity of Stakeholders for the Development of Community Based Plantation Forest at Three Selected Areas in Indonesia”, Between The Ministry of Forestry of Indonesia and International Tropical Timber Organization (ITTO), Jakarta.

Irawanti, S., Maryani, R., Effendi, R., Hakim, I., dan Dwiprabowo, H., 2008. Kebijakan Penetapan Harga Dasar Penjualan Kayu Hutan 
Tanaman Rakyat Dalam Rangka Pengembangan Hutan Tanaman Rakyat. Jurnal Analisis Kebijakan Kehutanan, 5(2):89100.

Iskandar, D., Paranoan, D., dan Djumlani, A., 2013. Implementasi Kebijakan Hutan Tanaman Rakyat di Kabupaten Bulungan, Kalimantan Timur. eJournal Administrative Reform, 1(2):525-537.

Mas’ud, E.I., dan Malamassam, D., 2011. Model Pembangunan Hutan Tanaman Rakyat Pola Mandiri di Desa Bacu-Bacu Kabupaten Barru, Sulawesi Selatan. Jurnal Hutan dan Masyarakat, 6(2):1-7.

Mulyana, D., Asmarahman, C., dan Fahmi, I., 2010. Bertanam Jabon. AgroMedia Pustaka, Jakarta.

Noordwijk, M.V., Budidarsono, S., Sakuntaladewi, N., Roshetko, J.M., Tata, H.., Galudra, G., dan Fay, C., 2007. Is Hutan Tanaman Rakyat A New Paradigm in Community Based Tree Planting in Indonesia? ICRAF Working Paper No 45, ICRAF Southeast Asia. Bogor.

Nugroho, B., 2011. Analisis Perbandingan Beberapa Skema Pinjaman untuk Pembangunan Hutan Tanaman Berbasis Masyarakat di Indonesia, Jurnal Manajemen Hutan Tropika, 17(2):79-88.

Nugroho, B., Dermawan, A., dan Putzel, L., 2013. Financing Smallholder Timber Planting in Indonesia: Mismatches Between Loan Scheme Attributes and Smallholder Borrowing Characteristics. International Forestry Review. 15(4):499-508.
Obidzinski, K. and Dermawan, A., 2010. Smallholder Timber Plantation Development in Indonesia: What is Preventing Progress? International Forestry Review. 12(4):339-348.

Riadi, F., Machfud, Tajuddin, B., dan Illah, S., 2011. Model Pengembangan Agroindustri Karet Alam Terintegrasi. Jurnal Teknologi Industri Pertanian, 21(3):146-153.

Rumboko, L., Race, D., dan Curtis, A., 2013. Optimising Community-Based Forest Management Policy in Indonesia: A Critical Review. Jurnal Ilmu Sosial dan Ilmu Politik 16(3):250-272.

Schneck, J., 2009. Assesing The Viability of HTRIndonesia Community Based Forest Plantation Program. Tesis. Master Project Submitted of Fulfillment of The Requirements for The Master of Environmental Management of Duke University, North Carolina.

Subarudi, 2014. Perkembangan Pembangunan Hutan Tanaman Rakyat di Provinsi Nusa Tenggara Barat dan Estimasi Harga Kayunya. Jurnal Penelitian Sosial dan Ekonomi Kehutanan, 11(3):199-209.

Suhirman, Z., Alamsyah, Zaini, A., Sulaiman, dan Nikoyan, A., 2012. Studi Perencanaan dan Penganggaran Bagi Pengelolaan Hutan Berbasis Masyarakat di Indonesia: Studi Kasus Provinsi Jambi, Kalimantan Barat, Nusa Tenggara Barat, Sulawesi Tenggara. Laporan Utama Sebagai Hasil Studi Lapangan. Kemitraan (Bagi Pembaruan Tata Kepemerintahan di Indonesia), Jakarta. 